\title{
Nitric Oxide and Prostanoids Protect the Renal Outer Medulla from Radiocontrast Toxicity in the Rat
}

\author{
Yoram Agmon, ${ }^{*}$ Hagit Peleg, ${ }^{*}$ Ziv Greenfeld, ${ }^{\star}$ Seymour Rosen, ${ }^{\ddagger}$ and Mayer Brezis ${ }^{*}$ \\ *Department of Medicine, Hadassah University Hospital, Mount-Scopus, Jerusalem, 91240, Israel; and ${ }^{\ddagger}$ Department of Pathology, \\ Beth Israel Hospital and Harvard Medical School, Boston, Massachusetts 02215
}

\begin{abstract}
Human radiocontrast nephrotoxicity is predicted by the presence of multiple risk factors, often associated with compromised renal circulation. To produce a simple model of radiocontrast nephropathy, rats were pretreated with indomethacin and $N \omega$-nitro-L-arginine methyl ester (L-NAME, to inhibit nitric oxide synthesis) before the administration of iothalamate. Acute renal failure consistently developed, with a decline in creatinine clearance from $1.05 \pm 0.10$ to $0.27 \pm 0.05 \mathrm{ml} / \mathrm{min}(P<0.001)$ associated with selective necrosis of $49 \pm 9 \%$ of medullary thick ascending limbs.

Hemodynamic studies using laser-Doppler probes revealed that when injected alone, iothalamate increased outer medullary blood flow to $196 \pm 25 \%$ of baseline $(P<0.001)$. Pretreatment by L-NAME or indomethacin both reduced basal medullary blood flow and transformed the medullary vasodilator response to radiocontrast into vasoconstriction, with a prolonged reduction of medullary blood flow to less then half of baseline. Combined administration of indomethacin, L-NAME, and iothalamate lowered medullary blood flow to $12 \pm 4 \%$ of baseline.

We conclude that prostanoids and nitric oxide have an important protective role in the renal response to radiocontrast material. Reduced synthesis of these vasoactive substances in renal/vascular diseases may predispose patients to radiocontrast nephropathy. (J. Clin. Invest. 1994. 94:1069-1075.) Key words: contrast media $•$ kidney failure, acute - laser-Doppler flowmetry - renal circulation • indomethacin
\end{abstract}

\section{Introduction}

The pathogenesis of radiocontrast nephropathy, a significant iatrogenic disease, remains poorly understood (1). While direct tubular toxicity, intraluminal obstruction, and immunological injury have been invoked, clinical characteristics (1-4) and experimental data (5-11) suggest that systemic and/or intrarenal hemodynamic changes may predispose to damage from radiocontrast media. The recent observations of defective endo-

This work was presented in part at the XII International Congress of Nephrology on 15 June 1993 in Jerusalem, Israel.

Address correspondence to Dr. Mayer Brezis, Department of Medicine, Hadassah University Hospital, Mount-Scopus, P.O. Box 24035, Jerusalem, 91240, Israel.

Received for publication 12 August 1993 and in revised form 14 January 1994.

J. Clin. Invest.

(C) The American Society for Clinical Investigation, Inc. 0021-9738/94/09/1069/07 \$2.00

Volume 94, September 1994, 1069-1075 thelial-dependent vasorelaxation in diabetes mellitus (12), hypertension (13), atherosclerosis (14), and heart failure (15) (conditions often present in human contrast nephropathy [14]) invite speculations about a potential role for endothelial dysfunction in the vulnerability to renal failure from radiocontrast.

Since nitric oxide and prostanoids are important mediators released by the endothelium, we designed a model of contrast nephropathy by pharmacological blockade of these substances before the administration of radiocontrast. We also studied intrarenal blood flow after radiocontrast administration, before or after inhibition of nitric oxide and prostaglandin synthesis, using laser-Doppler probes placed upon the kidney cortex and inserted into the outer medulla $(16,17)$. Our functional, pathological, and hemodynamic results indicate that these combined renal insults cause acute renal failure, characterized by outer medullary necrosis probably resulting from regional ischemia.

\section{Methods}

Adult male Sprague-Dawley rats (250-400 g body wt) were used for all experiments.

\section{Acute renal failure model}

Rats were kept in metabolic cages (Nalge Co., Rochester, NY) starting $24 \mathrm{~h}$ before the acute insults, with free access to tap water and standard rat chow. After a baseline 24-h urinary collection, the rats were anesthetized with an intraperitoneal injection of ketamine (Parke-Davis, Pontypool, Gwent, UK), $100 \mathrm{mg} / \mathrm{kg}$ body wt. The left femoral vein and artery were cannulated (PE-50; Clay Adams, Parsippany, NJ), and a baseline blood sample was drawn $(1 \mathrm{ml})$. Thereafter, one of the protocols described below was carried out. Then, the rats were returned to the metabolic cages for another 24-h urine collection, without access to water. At the end of this period, rats were anesthetized with an intraperitoneal injection of Inactin (Byk-Gulden, Konstanz, FRG; $100 \mathrm{mg} / \mathrm{kg}$ ), and a blood sample was drawn from the inferior vena cava at laparotomy. Then, in vivo renal fixation was performed with $1.25 \%$ gluteraldehyde (Eastman Kodak Co., Rochester, NY) in $0.1 \mathrm{M}$ phosphate buffer ( $\mathrm{pH}$ 7.4), through a 19-gauge needle inserted in the aorta, at a constant perfusion pressure of $\sim 140 \mathrm{mmHg}$.

The contrast material. Sodium iothalamate, $80 \%$ (Angio-Conray, Mallinckrodt Specialty Chemicals, St. Louis, MO), was injected through the arterial cannula over 2-3 $\mathrm{min}$, at the dosage of $6 \mathrm{ml} / \mathrm{kg}$ body weight (or $2.9 \mathrm{~g}$ of organically bound iodine $/ \mathrm{kg}$ body weight). As shown repeatedly (18-21), although high doses of radiocontrast administered to normal animals may induce transient reduction of glomerular filtration rate, sustained renal failure is rarely produced. To increase the likelihood of renal injury, the rats were preconditioned by inhibition of the synthesis of prostaglandin and/or nitric oxide. In the protocols, iothalamate administration is denoted CM (contrast material). ${ }^{1}$

Inhibition of the synthesis of prostaglandin. Indomethacin (Sigma

1. Abbreviations used in this paper: CM, contrast material; INDO, indomethacin; L-NAME, $N \omega$-nitro-L-arginine methyl ester; mTAL, medullary thick ascending limb; RBF, renal blood flow. 
Chemical Co., St. Louis, MO) was dissolved in phosphate buffer (pH 8.4 ) and administered intravenously at the dose of $10 \mathrm{mg} / \mathrm{kg}$. In the protocols, indomethacin administration is denoted as INDO.

Inhibition of the synthesis of nitric oxide. The competitive inhibitor of nitric oxide synthesis (22), N $\omega$-nitro-L-arginine methyl ester (LNAME; Sigma Chemical Co.), was dissolved in $0.9 \%$ saline and administered intravenously at the dose of $10 \mathrm{mg} / \mathrm{kg}$.

\section{EXPERIMENTAL GROUPS}

The various experimental protocols were as follows:

$C M(n=7)$. The rats were administered an intravenous injection of phosphate buffer ( $2 \mathrm{ml} / \mathrm{kg}$, serving as a control for indomethacin), followed $15 \mathrm{~min}$ later by $0.9 \%$ saline $(1 \mathrm{ml} / \mathrm{kg}$, serving as a control for L-NAME), followed $15 \mathrm{~min}$ later by iothalamate.

$L-N A M E(n=6)$. In addition to L-NAME, the rats were administered an intravenous injection of phosphate buffer and an intraarterial injection of $0.9 \%$ saline $(6 \mathrm{ml} / \mathrm{kg}$, serving as a control for iothalamate), $15 \mathrm{~min}$ before and $15 \mathrm{~min}$ after L-NAME, respectively.

INDO $(n=7)$. Indomethacin was administered, followed after 15 min by $0.9 \%$ saline, and followed after an additional $15 \mathrm{~min}$ by an intraarterial injection of $0.9 \%$ saline.

$L-N A M E+C M(n=8) .15 \mathrm{~min}$ after an injection of phosphate buffer, L-NAME was administered, followed after an additional $15 \mathrm{~min}$ by iothalamate.

$I N D O+C M(n=7)$. Indomethacin was administered, followed after $15 \mathrm{~min}$ by $0.9 \%$ saline, and followed after an additional $15 \mathrm{~min}$ by an intraarterial injection of iothalamate.

INDO + L-NAME $(n=8)$. Indomethacin was administered, followed after $15 \mathrm{~min}$ by L-NAME, followed after an additional $15 \mathrm{~min}$ by an intraarterial injection of $0.9 \%$ saline.

$I N D O+L-N A M E+C M(n=12)$. Indomethacin was administered, followed after $15 \mathrm{~min}$ by L-NAME, and followed after an additional $15 \mathrm{~min}$ by iothalamate.

\section{MORPHOLOGICAL STUDIES}

After perfusion fixation, kidneys were sliced and postfixed in buffered $2 \% \mathrm{OsO}_{4}$, dehydrated, and embedded in an araldite-Epon 812 mixture, and 3-mm sections were cut, containing cortex and outer medulla. Stained with $1 \%$ methylene blue, the sections were examined in a blinded fashion, as described previously $(18,23,24)$. In the inner stripe of the outer medulla, necrotic medullary thick ascending limbs (mTALs) were counted and expressed as a percentage of the total number of tubules present.

\section{Hemodynamic studies}

These studies were designed to evaluate the effects of pretreatments by L-NAME and/or indomethacin, upon the intrarenal microvascular response to iothalamate. The laser-Doppler methodology was similar to that used in previous studies $(16,17,25-29)$. Unlike Nygren et al. (27), we examined blood flow in the outer medulla rather than in the papilla (which can remarkably differ, as shown in ischemia reflow [28]), and readings were obtained simultaneously from cortex and medulla.

\section{ANIMAL PREPARATION}

Rats were anesthetized with an intraperitoneal injection of Inactin (BykGulden; an average of $60 \mathrm{mg} / \mathrm{kg}$ body wt), and catheters were placed in the trachea (PE-250; Clay Adams), left femoral vein, and artery (PE-50; Clay Adams). Normal saline with bovine serum albumin at a concentration of $\sim 4.5 \mathrm{~g} / \mathrm{dl}$ was infused intravenously at a rate of $5 \mathrm{ml} /$ $h$ during all experiments, and intraarterial blood pressure was monitored continuously. The left kidney was exposed through a midline incision, decapsulated, and mechanically fixed. The temperature of the kidney was measured by a needle probe (Omega Engineering, Inc., Stamford, CT) and kept at $\sim 37^{\circ} \mathrm{C}$ with a heating lamp and intermittently dripping warm mineral oil. The urinary bladder was incised to prevent urinary retention.

\section{MEASUREMENT OF REGIONAL RENAL BLOOD FLOW}

Regional blood flow was measured by laser-Doppler probes mounted on micromanipulators and placed in two locations: $(a)$ superficial cortex: a blunt probe ( $\varnothing 1 \mathrm{~mm}$, model PF 303; Perimed, Stockholm, Sweden) was placed over the kidney cortex; and $(b)$ outer medulla: a fine needle probe ( $\varnothing 0.45 \mathrm{~mm}$, model PF 302; Perimed) was inserted $3.5-4.5 \mathrm{~mm}$ into the renal parenchyma, perpendicularly to surface, near the center of kidney.

The laser-Doppler probes were connected to flowmeters (models PF2B and PF3; Perimed) allowing simultaneous measurements in cortex and medulla.

Principles of measurement. The laser-Doppler flowmetry allows measurement of microvascular blood perfusion through tissues, using the Doppler shift, i.e., the change in frequency that light waves undergo when reflected by objects in motion. The laser beam emitted from the probe interacts with moving cells in the tissue (primarily erythrocytes) resulting in a Doppler shift of the light returned to the flowmeter. The frequency of this shift relates to the velocity of erythrocytes, while the magnitude of the signal is correlated with the concentration of erythrocytes in the tissue. Flux (the product of velocity and concentration of erythrocytes) is computed from the product of frequency and magnitude of the Doppler signal. The flux measured refers to a given tissue volume adjacent to the probe (a hemisphere with a diameter equal to the specific probe diameter). The principles of laser-Doppler flowmetry, the details of the assumptions, calculations, and standardization, including application to the renal tissue, have been reviewed elsewhere $(30,31)$. Renal cortical flux, estimated by laser-Doppler, correlated well with the cortical blood flow measured by radiolabeled microspheres and with the total renal blood flow obtained by an electromagnetic probe (31).

Limitations and validation of laser-Doppler flowmetry in the renal medulla. As for other tissues, since no reliable calibration of the blood flux can be done, only relative changes from baseline in response to a perturbation can be determined. In this study, measurements were done after an average of $30 \mathrm{~min}$ of equilibration, during which baseline flux values stabilized (signals read after killing the experimental animals, often unequal to zero, were subtracted from all flux values). The ambient light was maintained constant, to avoid artifacts from variations in light intensity.

Several theoretical considerations may limit the application of the laser-Doppler flowmetry to the medulla: the countercurrent disposition of the vasa recta may violate the assumption of randomness of signals from the capillary network (30); with the relatively high fraction of erythrocyte volume in the medullary tissue, the proportionality of the signal to erythrocyte velocity may or may not be adequately corrected by the linearizer included in the PF2B and PF3 Perimed models (31). Nevertheless, several studies have indicated a satisfactory agreement between laser-Doppler flowmetry and other methods for measurement of medullary blood flow, such as ${ }^{51} \mathrm{Cr}$-labeled red blood cell accumulation (25) and videomicroscopy (26), in the papilla.

With the development of thin single-fiber laser probes, needle probes have been inserted into the outer medulla $(16,17,28,29,32,33)$. Microcirculatory changes after ischemia reflow disclosed a selective decrease in outer medullary blood flow correlated with increased regional trapping of erythrocytes (28). Variations in outer medullary blood flow (measured by laser-Doppler) correlated with changes in regional cytochrome oxidative state (32). Puncture of the outer medulla produced no changes in whole kidney blood flow, glomerular filtration, and electrolyte excretion (33). Insertion of the probe perpendicularly to cortico-medullary axis ensures minimal disruption of the vasculature supplying blood to the tissue examined. Simultaneous measurements with a laser-Doppler probe and $\mathrm{a} \mathrm{O}_{2}$ microelectrode have revealed little perturbations in basal tissue oxygenation within the outer medulla (Brezis, M., unpublished observations) and have shown correlated changes in flux and $\mathrm{pO}_{2}$ after indomethacin (16) or furosemide (29). One specific problem encountered is the correct positioning of the probe in the outer medulla. Experience with oxygen microelectrodes has taught us that the outer medulla is regularly reached by insertion of the probe perpendicular to the renal surface and near the center of the kidney, at a distance of $\sim 4 \mathrm{~mm}$ from its lateral border, to a depth of $3.5-4.5 \mathrm{~mm}$ into the renal parenchyma (for rats weighing $\sim 300-400 \mathrm{~g}$ ). In the present study, adequate location of the needle probe in the outer medulla was confirmed macroscopically at the end of each experiment by kidney 
Table I. Plasma Creatinine and Creatinine Clearance before (Day 0) and after the Acute Insults (Day 1), and Semiquantitative Evaluation of mTAL Necrosis (at the End of Day 1) in the Experimental Groups of the Acute Renal Failure Model

\begin{tabular}{|c|c|c|c|c|c|}
\hline \multirow[b]{2}{*}{ Experimental groups } & \multicolumn{2}{|c|}{ Plasma creatinine } & \multicolumn{2}{|c|}{ Creatinine clearance } & \multirow{2}{*}{$\begin{array}{l}\text { Proportion of mTALs } \\
\text { with necrosis }\end{array}$} \\
\hline & Day 0 & Day 1 & Day 0 & Day 1 & \\
\hline & \multicolumn{2}{|c|}{ emolliter } & \multicolumn{2}{|c|}{$\mathrm{ml} / \mathrm{min}$} & $\%$ \\
\hline $\mathrm{CM}(n=7)$ & $59 \pm 5$ & $66 \pm 4$ & $1.17 \pm 0.23$ & $0.64 \pm 0.11$ & 0 \\
\hline L-NAME $(n=6)$ & $75 \pm 4$ & $75 \pm 2$ & $1.07 \pm 0.11$ & $0.96 \pm 0.10$ & $1 \pm 1$ \\
\hline INDO $(n=7)$ & $75 \pm 7$ & $72 \pm 5$ & $0.70 \pm 0.10$ & $0.70 \pm 0.07$ & 0 \\
\hline L-NAME + CM $(n=8)$ & $65 \pm 3$ & $97 \pm 11$ & $1.22 \pm 0.08$ & $0.48 \pm 0.10^{*}$ & $18 \pm 6$ \\
\hline $\mathrm{INDO}+\mathrm{CM}(n=7)$ & $75 \pm 3$ & $91 \pm 9$ & n.a. & $0.41 \pm 0.06^{*}$ & 0 \\
\hline INDO + L-NAME $(n=8)$ & $78 \pm 8$ & $131 \pm 11$ & $0.93 \pm 0.15$ & $0.48 \pm 0.06^{*}$ & $2 \pm 1$ \\
\hline INDO + L-NAME + CM $(n=12)$ & $69 \pm 3$ & $178 \pm 19^{\ddagger}$ & $1.05 \pm 0.10$ & $0.27 \pm 0.05^{* 3}$ & $49 \pm 9^{11}$ \\
\hline
\end{tabular}

${ }^{\ddagger} P<0.01$ vs INDO + L-NAME, $P<0.001$ vs all other groups; ${ }^{*} P<0.001$ vs L-NAME and vs INDO; ${ }^{8} P<0.05$ vs CM and vs INDO + L-NAME; " $P<0.002$ vs L-NAME $+\mathrm{CM}, P<0.001$ vs all other groups. n.a., not available.

dissection, as in previous work $(16,17,29)$, and only experiments with satisfactory positioning of the intraparenchymal probe were used (resulting in an exclusion of $\sim 10 \%$ of experiments).

EXPERIMENTAL PROTOCOLS

The following experimental protocols were studied:

$C M$. Iothalamate, $6 \mathrm{ml} / \mathrm{kg}$, was given intravenously into the left femoral vein over a period of $2-3 \min (n=6)$. Iothalamate was administered intravenously because intraarterial injections cause fasciculations of the lower limb muscles (18), predisposing to movement artifacts in the laser-Doppler system.

$L-N A M E+C M$. L-NAME, $10 \mathrm{mg} / \mathrm{kg}$, was given as an intravenous bolus, followed after $30 \mathrm{~min}$ by iothalamate, as above $(n=6)$.

$I N D O+C M$. Indomethacin, $5 \mathrm{mg} / \mathrm{kg}$, was given as an intravenous bolus, followed after $30 \mathrm{~min}$ by iothalamate, as above $(n=6)$.

$I N D O+L-N A M E+C M$. Indomethacin was followed after $30 \mathrm{~min}$ by L-NAME and after an additional $30 \mathrm{~min}$ by iothalamate, as above $(n=3)$.

Changes in regional renal blood flow were followed for an hour after the injection of iothalamate.

\section{Statistical analysis}

Data are presented as mean \pm SE. For the acute renal failure model, analysis of variance was used to compare the different experimental groups, with the baseline values as covariates for renal function parameters. The Newman-Keuls test was used for post-hoc comparisons. For renal hemodynamic studies, regional blood flow was compared with baseline using the Student's paired $t$ test.

\section{Results}

Acute renal failure model. Table I shows plasma creatinine, creatinine clearance, and scoring of histological injury in the different experimental groups. Iothalamate, L-NAME, or indomethacin alone induced little or no renal dysfunction, with minimal morphological damage. L-NAME or indomethacin before iothalamate, or their combination without radiocontrast, led to renal dysfunction without consistent injury to mTALs. The administration of radiocontrast after combined pretreatment with indomethacin and L-NAME induced marked renal failure, with a reduction of creatinine clearance to $\sim 25 \%$ of baseline associated with necrosis of nearly half of mTALs.

The major morphological changes in our in vivo model were located at the inner stripe of the outer medulla, consisting of
mTAL necrosis, as shown in Fig. 1. Tubular damage was maximal in the interbundle zone, remote from the vascular bundles, while mTALs adjacent to vasa recta were generally intact. Focal necrosis of the pars recta of the proximal tubule $\left(\mathrm{S}_{3}\right)$ was noted in the outer stripe of the outer medulla when mTAL damage was most extreme. By contrast to these striking pathological findings in the renal medulla, there was no necrosis of cortical nephron segments. Vacuolar changes in the proximal tubular epithelium were observed, as previously described (18).

Hemodynamic studies. Fig. 2 illustrates the changes in cortical and outer medullary blood flow after iothalamate, with or without pretreatment by L-NAME or indomethacin. In the cortex, iothalamate induced transient reductions in blood flow, regardless of pretreatment. By contrast, in the outer medulla, the blood flow response to iothalamate was modified completely by L-NAME or indomethacin.

In response to iothalamate, cortical blood flow dropped sharply to $17 \pm 6 \%$ of baseline $(n=6 ; P<0.0001)$, rapidly returning towards baseline (within less than an hour). By contrast, administration of iothalamate led to a sustained increase in medullary blood flow to $196 \pm 25 \%$ of baseline $(n=6 ; P$ $<0.001$ ).

Pretreatment with L-NAME lowered both cortical and medullary flow to $61 \pm 7 \%$ of baseline $(n=6 ; P<0.005)$ and $61 \pm 7 \%(n=6 ; P<0.005)$, respectively, $30 \mathrm{~min}$ after its administration (data not shown on Fig. 2). After pretreatment with L-NAME, as seen in Fig. 2, iothalamate caused a transient decline in cortical flow to $52 \pm 8 \%$ of basal $(n=6 ; P<0.005)$, returning towards baseline values within less than an hour. In the renal medulla, the previously observed hyperemic response to iothalamate was no longer present. On the contrary, medullary blood flow further decreased to $47 \pm 9 \%$ of basal $(n=6$; $P<0.005$ ), and this vasoconstrictive response persisted for at least $1 \mathrm{~h}$ after iothalamate administration. The combination of L-NAME and iothalamate lowered medullary flow to $35 \pm 13 \%$ of initial baseline recorded before L-NAME administration ( $n$ $=6 ; P<0.005$ ).

Pretreatment with indomethacin selectively reduced outer medullary blood flow to half of baseline without changes in cortical blood flow, as described recently (16). After pretreatment with indomethacin, as seen in Fig. 2 , in the cortex, iothalamate caused a transient decline in flow to $42 \pm 13 \%$ of basal ( $n$ 

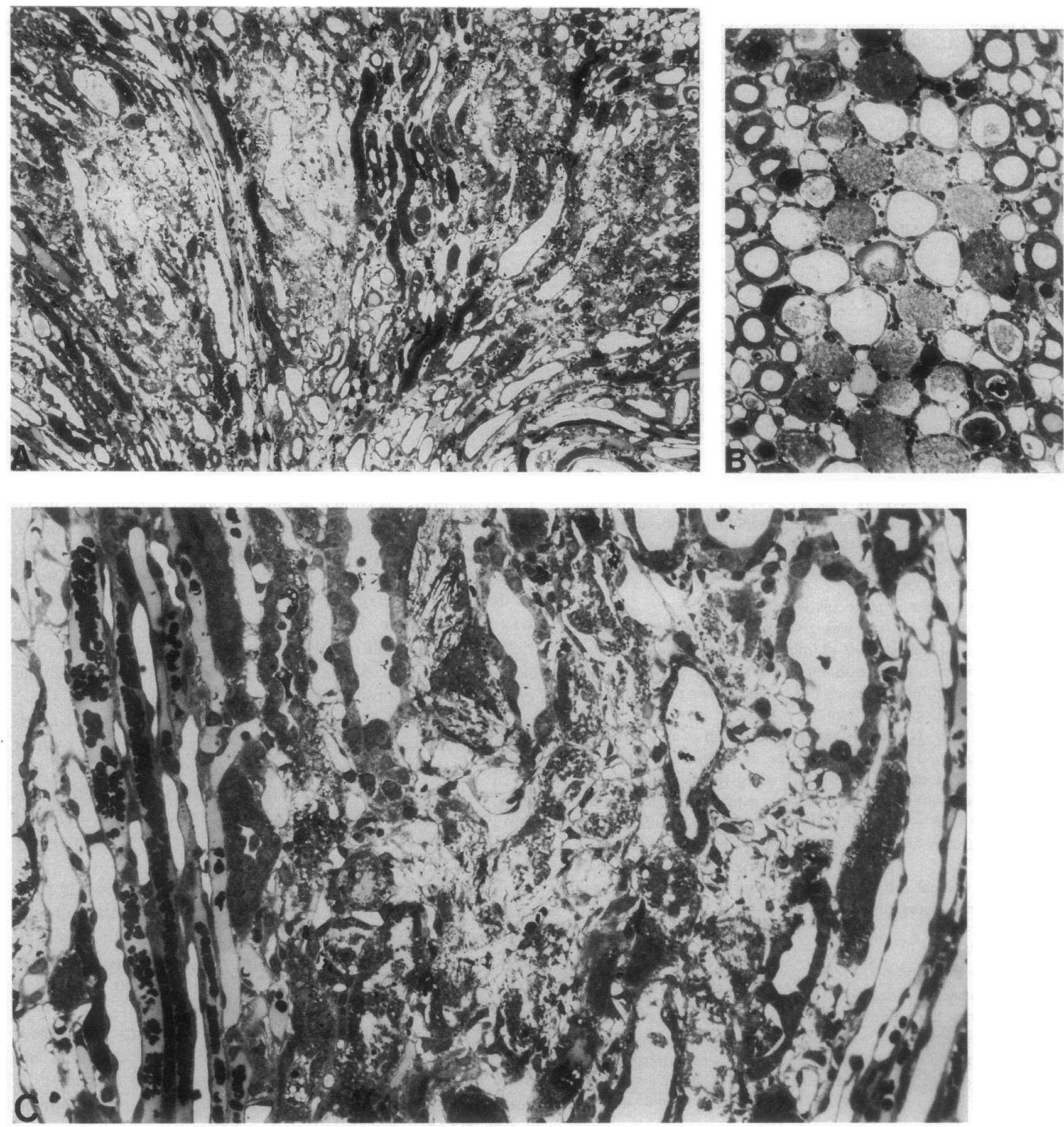

Figure 1. Renal histology of a rat treated with indomethacin, L-NAME, and iothalamate, $24 \mathrm{~h}$ before fixation. At low power $(A)$, the inner stripe of the outer medulla shows extensive necrosis. At higher power, both in horizontal $(B)$ and sagittal sections $(C)$, extensive necrosis of mTALs can be appreciated. mTALs adjacent to vasa recta are preserved (lateral aspects of both photographs). $\times 86, \times 245$, and $\times 245$, for $A, B$, and $C$, respectively.

$=6 ; P<0.01$ ), returning towards baseline values within less than an hour. In the renal medulla, the previously observed hyperemic response to iothalamate in the intact rat was again eliminated. Medullary blood flow further decreased to $45 \pm 6 \%$ of basal ( $n=6 ; P<0.001$ ), and this vasoconstrictive response persisted for at least $1 \mathrm{~h}$ after iothalamate administration.

Fig. 3 illustrates the cumulative hemodynamic effects of the consecutive administration of indomethacin, L-NAME, and iothalamate. At the end of all treatments, cortical blood flow was reduced to $45 \pm 9 \%$ of initial baseline $(n=3 ; P<0.05)$, while medullary blood flow was reduced to $12 \pm 4 \%$ of initial baseline $(n=3 ; P<0.005)$.

\section{Discussion}

The combined acute inhibition of the synthesis of nitric oxide and prostaglandin predisposed to consistent and severe renal failure from iothalamate, associated with extensive necrosis of 


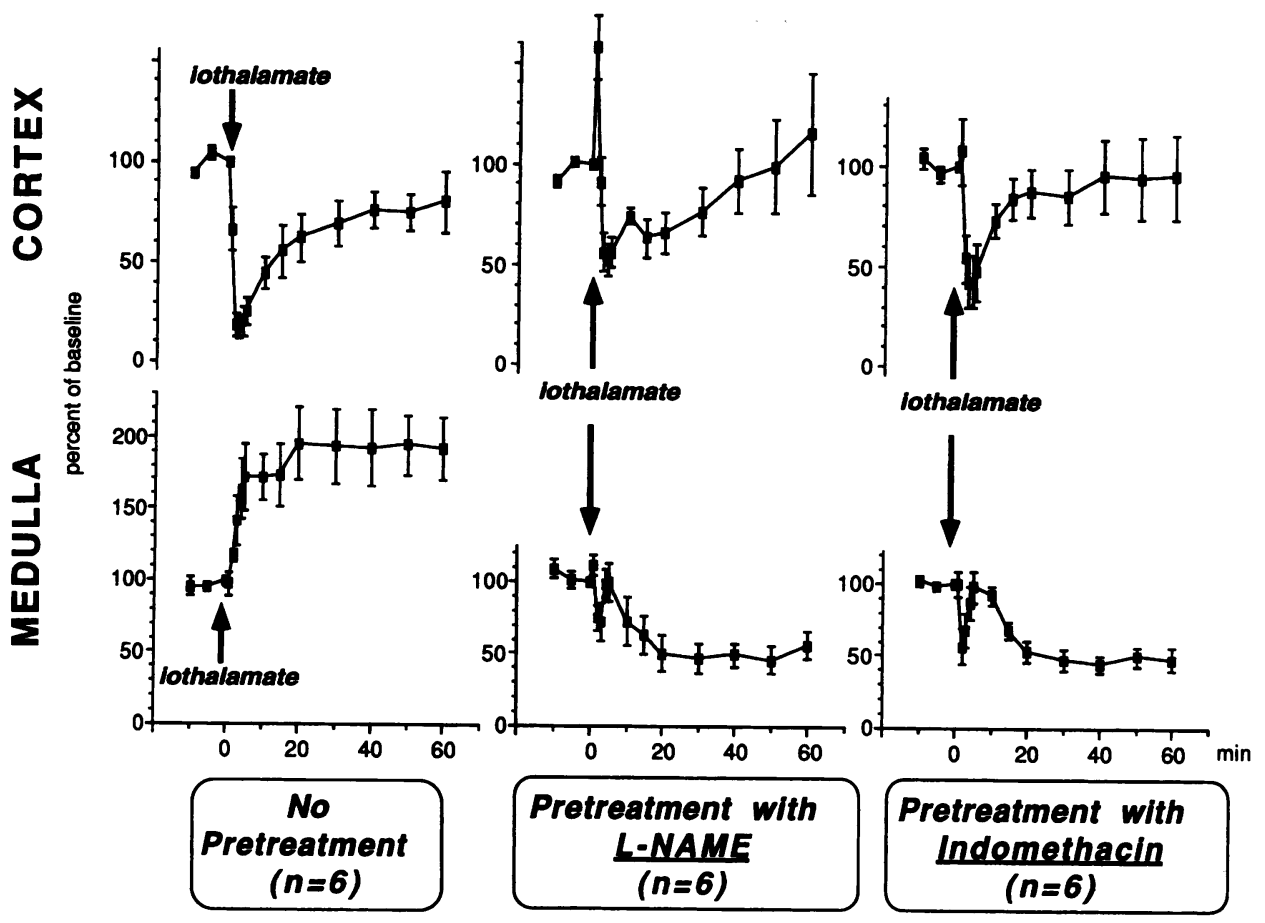

Figure 2. Changes in cortical and outer medullary blood flow after iothalamate administration with or without pretreatment by L-NAME or indomethacin.
mTALs. This model of radiocontrast nephropathy is remarkably simple, without the need for chronic preparations (e.g., uninephrectomy and chronic salt depletion, as in references 18 and 34). As shown in Table I, the combined inhibition of nitric oxide and prostaglandin synthesis appeared to be both necessary and sufficient to predispose rats to severe renal injury from radiocontrast.

No simple relationship existed between renal failure and mTAL damage. The combinations of indomethacin with contrast or with L-NAME possibly induced reversible renal vasoconstriction without apparent tubular damage. Extensive mTAL necrosis, after INDO + L-NAME + CM, may contribute to a further decrease in glomerular filtration rate (by backleak, obstruction, or tubuloglomerular feedback) and/or may lead to delayed recovery of kidney function (preliminary observations in these animals indicate persisting renal failure for several days

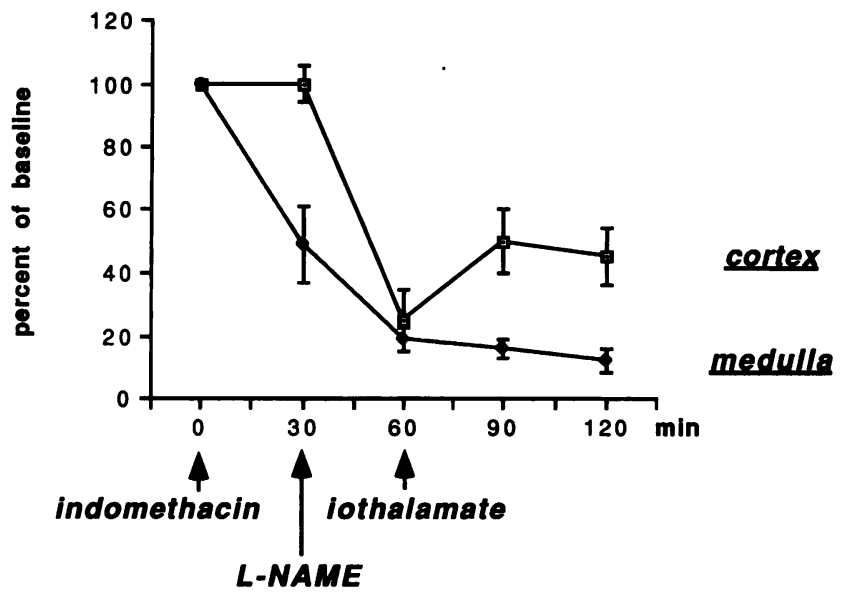

Figure 3. Changes in cortical and outer medullary blood flow after sequential administration of indomethacin, L-NAME, and iothalamate. associated with selective medullary damage at various phases of repair).

Renal blood flow (RBF) shows a transient decline in response to radiocontrast administration $(5,6,8,11)$, consistent with the present observations in the cortex, which normally receives the bulk of RBF. Alterations of total RBF after radiocontrast, apparently absent in humans (4), may overlook significant intrarenal microcirculatory changes, specifically in the outer medulla, which normally receives one-tenth of RBF and may be particularly vulnerable to ischemia $(35,36)$. The present study used a laser-Doppler needle probe inserted into the kidney, in an attempt to define outer medullary blood flow responses to radiocontrast.

As shown previously (23), radiocontrast induces intrarenal hypoxia, possibly related to hemodynamic changes and/or increased reabsorptive work because of osmotic load. In the present study, when administered alone, iothalamate doubled outer medullary blood flow. This medullary hyperemia, apparently insufficient to prevent hypoxia (23), may derive from the local release of vasodilator substances in response to the radiocontrast or to the hypoxia itself. Radiocontrast increases urinary adenosine $(8)$, a potent medullary vasodilator $(17,37)$. Radiocontrast also increases urinary prostaglandin $\mathrm{E}_{2}(38)$, a major vasodilator prostaglandin in the rat kidney $(16,39)$. Whether nitric oxide is directly affected by radiocontrast is unknown, but hypoxia may stimulate its release (40). As indomethacin markedly enhances nitrite excretion (41), prostanoids and nitric oxide could act in concert to protect from regional hypoxia, particularly in the renal medulla.

Pharmacological blockade of these medullary vasodilator mechanisms by L-NAME or indomethacin reduced medullary blood flow to about half of baseline and radically modified the response to radiocontrast. After pretreatment with either LNAME or indomethacin, the previously observed hyperemic response to iothalamate was replaced by an apparently paradoxical further decline in outer medullary blood flow by nearly $50 \%$. 
Inhibition of nitric oxide or prostaglandin synthesis unmasked a vasoconstrictive property of radiocontrast, possibly mediated by endothelin (9-11). This reversal of vasoactive response is reminiscent of the effect of endothelial dysfunction in other vascular beds, such as in atherosclerotic coronary arteries, which paradoxically constrict in response to acetylcholine (14).

The combination of indomethacin, L-NAME, and iothalamate reduced medullary blood flow to nearly $10 \%$ of baseline and induced selective necrosis of mTALs, probably related to medullary hypoxia. The inner stripe of the outer medulla is vulnerable to hypoxia because of the high metabolic activity of mTALs coupled with a meager oxygen supply to this region (35). Homeostasis of medullary oxygenation may depend on prostanoids (16), nitric oxide (34), and adenosine (42), by either maintaining blood flow and/or decreasing oxygen consumption $(36,43)$. The selective outer medullary ischemia observed in our model resembles the situation after renal artery occlusion in the rat, where blood flow to the outer medulla is reduced to $16 \%(28)$ and tubular necrosis predominates in this area.

In the present experiments, the specificity of the effect of nitric oxide inhibition remains somewhat uncertain, i.e., could similar results be obtained with the use of other vasoconstrictive agents, such as angiotensin or epinephrine? In a previous study, angiotensin II given in combination with indomethacin also predisposed to injury from radiocontrast, albeit considerably less than in the present report (44). Some vasoconstrictive effects of nitric oxide inhibition may in fact be mediated by angiotensin (45), while, as in the lung, chronic hypoxemia may in itself induce secondary defects in nitric oxide release (46): other vasoconstrictive agents could therefore mimic the effects of nitric oxide inhibition. Recent reports of a remarkably high activity of inducible nitric oxide synthase in the mTAL (47, 48 ) are consistent with an important local role for nitric oxide in the normal balance of medullary oxygenation.

Impaired endothelium-derived vasorelaxation in diabetes mellitus, hypertension, atherosclerosis, and heart failure (1215 ) results in paradoxical vasoconstriction (14) or reduced vasodilatation $(49,50)$ and regional hypoxia. Since these diseases are frequently associated with radiocontrast toxicity (1-4), endothelial dysfunction may predispose patients to renal injury from contrast.

\section{Acknowledgments}

The authors are grateful to Dr. Franklin Epstein for helpful suggestions. This work was supported by grants from the United States-Israel Binational Science Foundation and from the National Institutes of Health (grant DK-18078). Ms. Peleg received support from the Kornfeld Foundation.

\section{References} 740.

1. Berns, A. S. 1989. Nephrotoxicity of contrast media. Kidney Int. 36:730-

2. Taliercio, C. P., R. E. Vlietstra, L. D. Fisher, and J. C. Burnett, Jr. 1986. Risks for renal dysfunction with cardiac angiography. Ann. Intern. Med. 104:501 504.

3. Rich, M. W., and C. A. Crecelius. 1990. Incidence, risk factors, and clinical course of acute renal insufficiency after cardiac catheterization in patients 70 years of age or older. Arch. Intern. Med. 150:1237-1242.

4. Weisberg, L. S., P. B. Kurnik, and B. R. C. Kurnik. 1992. Radiocontrastinduced nephropathy in humans: role of renal vasoconstriction. Kidney Int. 41:1408-1415.

5. Larson, T. S., K. Hudson, J. I. Mertz, J. C. Romero, and F. G. Knox. 1983.
Renal vasoconstrictive response to contrast medium, the role of sodium balance and the renin-angiotensin system. J. Lab. Clin. Med. 101:385-391.

6. Bakris, G. L., and J. C. Burnett. 1985. A role for calcium in radiocontrastinduced reductions in renal hemodynamics. Kidney Int. 27:465-468.

7. Margulies, K. B., L. J. McKinley, P. G. Cavero, and J. C. Burnett, Jr. 1990 Induction and prevention of radiocontrast-induced nephropathy in dogs with heart failure. Kidney Int. 38:1101-1108.

8. Arend, L. J., G. L. Bakris, J. C. Burnett, C. Megerian, and W. S. Spielman. 1987. Role for intrarenal adenosine in the renal hemodynamic response to contrast media. J. Lab. Clin. Med. 110:406-411.

9. Margulies, K. B., F. L. Hildebrand, D. M. Heublein, and J. C. Burnett, Jr. 1991. Radiocontrast increases plasma and urinary endothelin. J. Am. Soc. Nephrol. 2:1041-1045.

10. Heyman, S. N., B. A. Clark, N. Kaiser, K. Spokes, S. Rosen, M. Brezis, and F. H. Epstein. 1992. Radiocontrast agents induce endothelin release in vivo and in vitro. J. Am. Soc. Nephrol. 3:58-65.

11. Cantley, L. G., K. Spokes, B. Clark, A. Kuhlik, and F. H. Epstein. 1992. An endothelin receptor antagonist decreases the effect of iothalamate on renal blood flow. J. Am. Soc. Nephrol. 3:434a. (Abstr.)

12. Calver, A., J. Collier, and P. Vallance. 1992. Inhibition and stimulation of nitric oxide synthesis in the human forearm arterial bed of patients with insulindependent diabetes. J. Clin. Invest. 90:2548-2554.

13. Panza, J. A., A. A. Quyyumi, J. E. Brush, and S. E. Epstein. 1990. Abnormal endothelium-dependent relaxation in patients with essential hypertension. N. Engl. J. Med. 323:22-27.

14. Ludmer, P. L., A. P. Selwyn, T. L. Shook, R. R. Wayne, G. H. Mudge, R. W. Alexander, and P. Ganz. 1986. Paradoxical vasoconstriction induced by acetylcholine in atherosclerotic coronary arteries. N. Engl. J. Med. 315:10461051 .

15. Kubo, S. H., T. S. Rector, A. J. Bank, R. E. Williams, and S. M. Heifetz. 1991. Endothelium-dependent vasodilation is attenuated in patients with heart failure. Circulation. 84:1589-1596.

16. Agmon, Y., and M. Brezis. 1993. Effects of nonsteroidal antiinflammatory drugs upon intrarenal blood flow: selective medullary hypoperfusion. Exp. Nephrol. 1:357-363.

17. Agmon, Y., D. Dinour, and M. Brezis. 1993. Disparate effects of intrarenal adenosine $\mathrm{A}_{1}$ and $\mathrm{A}_{2}$ agonists upon intrarenal blood flow. Am. J. Physiol. 34:F802F806.

18. Heyman, S. N., M. Brezis, C. A. Reubinoff, Z. Greenfeld, C. Lechene, F. H. Epstein, and S. Rosen. 1988. Acute renal failure with selective medullary injury in the rat. J. Clin. Invest. 82:401-412.

19. Vaamonde, C. A., R. T. Bier, R. Papendick, H. Alpert, W. Gouvea, B. Owens, and V. Pardo. 1989. Acute and chronic renal effects of radiocontrast in diabetic rats. Role of anesthesia and risk factors. Invest. Radiol. 24:206-218.

20. Misson, R. T., and R. E. Cutler. 1985. Radiocontrast-induced renal failure. West. J. Med. 142:657-664.

21. Vari, R. C., L. A. Nataragan, S. A. Whitescarver, B. A. Jackson, and C. M. Ott. 1988. Induction, prevention and mechanisms of contrast media-induced acute renal failure. Kidney Int. 33:699-707.

22. Romero, J. C., V. Lahera, M. G. Salom, and M. L. Biondi. 1992. Role of the endothelium-dependent relaxing factor nitric oxide on renal function. $J$. Am. Soc. Nephrol. 2:1371-1387.

23. Heyman, S. N., M. Brezis, F. H. Epstein, K. Spokes, P. Silva, and S. Rosen. 1991. Early renal medullary hypoxic injury from radiocontrast and indomethacin. Kidney Int. 40:632-642.

24. Brezis, M., S. Rosen, P. Silva, and F. H. Epstein. 1984. Selective vulnerability of the medullary thick ascending limb to anoxia in the isolated perfused rat kidney. J. Clin. Invest. 73:182-190.

25. Roman, R. J., and C. Smits. 1986. Laser-Doppler determination of papillary blood flow in young and adult rats. Am. J. Physiol. 251:F115-F124.

26. Fenoy, F. J., and R. J. Roman. 1991. Effect of volume expansion on papillary blood flow and sodium excretion. Am. J. Physiol. 260:F813-F822.

27. Nygren, A., H. R. Ulfendahl, P. Hansell, and U. Erikson. 1988. Effects of intravenous contrast media on cortical and medullary blood flow in the rat kidney. Invest. Radiol. 23:753-761.

28. Hellberg, P. O. A., O. Kallskog, and M. Wolgast. 1991. Red cell trapping and postischemic renal blood flow. Differences between the cortex, outer and inner medulla. Kidney Int. 40:625-631.

29. Brezis, M., Y. Agmon, and F. H. Epstein. 1994. Determinants of intrarenal oxygenation. I. Effects of diuretics. Am. J. Physiol. In press.

30. Bonner, R. F., and R. Nossal. 1990. Principles of laser-Doppler flowmetry. In Laser-Doppler Blood Flowmetry. A. P. Shepherd and P. A. Öberg, editors. Kluwer Academic Publishers, Boston. 17-46.

31. Roman, R. J. 1990. Renal blood flow. In Laser-Doppler Blood Flowmetry A. P. Shepherd and P. A. Öberg, editors. Kluwer Academic Publishers, Boston. 289-304.

32. Atkins, J. L., and S. P. Lankford. 1991. Changes in cytochrome oxidation in outer and inner stripes of outer medulla. Am. J. Physiol. 261:F849-F857.

33. Hansel, P., A. Nygren, and J. Ueda. 1990. Influence of verapamil on regional renal blood flow: a study using multichannel laser-Doppler flowmetry. Acta Physiol. Scand. 139:15-20. 
34. Brezis, M., S. N. Heyman, D. Dinour, F. H. Epstein, and S. Rosen. 1991 Role of nitric oxide in renal medullary oxygenation. Studies in isolated and intact rat kidneys. J. Clin. Invest. 88:390-395.

35. Brezis, M., S. Rosen, P. Silva, and F. H. Epstein. 1984. Renal ischemia: a new perspective. Kidney Int. 26:375-383.

36. Brezis, M., S. Rosen, and F. H. Epstein. 1989. The pathophysiological implications of medullary hypoxia. Am. J. Kidney Dis. 13:253-258.

37. Miyamoto, M., Y. Yagil, T. Larson, C. Robertson, and R. L. Jamison. 1988. Effects of intrarenal adenosine on renal function and medullary blood flow in the rat. Am. J. Physiol. 255:F1230-F1234.

38. Cantley, L. G., K. Spokes, B. Clark, E. McMahon, J. Carter, and F. H. Epstein. 1993. Role of endothelin and prostaglandins in radiocontrast-induced renal artery constriction. Kidney Int. 44:1217-1223.

39. Badr, K. F., and H. R. Jacobson. 1991. Arachidonic acid metabolites and the kidney. In The Kidney. 4th Ed. B. M. Brenner and F. C. Rector, editors W. B. Saunders Co., Philadelphia. 584-619.

40. Busse, R., A. Mulsch, I. Fleming, and M. Hecker. 1993. Mechanisms of nitric oxide release from vascular endothelium. Circulation. 87(Suppl. V):V18V25.

41. Miller, M. J. S., S. Eloby-Childress, B. Snapp, S. Chotinaruemol, V. L. Steen, and D. A. Clark. 1993. Urinary nitrite excretion in premature infants: effects of transfusion or indomethacin. Acta Paediatr. 82:291-295.

42. Dinour, D., and M. Brezis. 1991. Effects of adenosine on intrarenal oxygenation. Am. J. Physiol. 261:F787-F791.
43. Brezis, M., and F. H. Epstein. 1993. Cellular mechanisms of acute ischemic injury in the kidney. Annu. Rev. Med. 44:27-37.

44. Brezis, M., Z. Greenfeld, A. Shina, and S. Rosen. 1990. Angiotensin II augments medullary hypoxia and predisposes to acute renal failure. Eur. J. Clin. Invest. 20:199-207.

45. Takenaka, T., K. D. Mitchell, and L. G. Navar. 1993. Contribution of angiotensin II to renal hemodynamic and excretory responses to nitric oxide synthesis inhibition in the rat. J. Am. Soc. Nephrol. 4:1046-1053.

46. Adnot, S., B. Raffestin, S. Eddahibi, P. Braquet, and P.-E. Chabrier. 1991. Loss of endothelium-dependent relaxant activity in the pulmonary circulation of rats exposed to chronic hypoxia. J. Clin. Invest. 87:155-162.

47. Morrissey, J., R. McCracken, H. Kaneto, M. Vehaskari, D. Montani, and S. Klahr. 1993. Location of an inducible nitric oxide synthase (NOS) in the medullary thick ascending limb. J. Am. Soc. Nephrol. 4:560a. (Abstr.)

48. Mohaupt, M. G., K. Y. Ahn, K. M. Madsen, C. S. Wilcox, C. C. Tisher, and B. C. Kone. 1993. Expression and distribution of nitric oxide synthase (NOS) isoforms in rat kidney. Poster presented at the Annual Meeting of the American Society of Nephrology, Boston, Massachusetts.

49. Quyyumi, A. A., R. O. Cannon, III, J. A. Panza, J. G. Diodati, and S. E. Epstein. 1992. Endothelial dysfunction in patients with chest pain and normal coronary arteries. Circulation. 86:1864-1891.

50. Egashira, K., T. Inou, Y. Hirooka, A. Yamada, Y. Urabe, and A. Takeshita. 1993. Evidence of impaired endothelium-dependent coronary vasodilation in patients with angina pectoris and normal coronary angiograms. N. Engl. J. Med. 328:1659-1664. 